\title{
Homozygous mutation within the conserved Ala-Phe-Asn-Glu-Thr motif of exon 7 of the LH receptor causes male pseudohermaphroditism
}

\author{
Jörg Gromoll, Angela Schulz ${ }^{1}$, Heike Borta ${ }^{2}$, Thomas Gudermann² ${ }^{2}$, Katja J Teerds ${ }^{3}$, Annette Greschniok ${ }^{4}$, \\ Eberhard Nieschlag and Fritz J Seif ${ }^{4}$ \\ Institute of Reproductive Medicine of the University, Münster, Germany, ${ }^{1}$ Institute of Pharmacology, Free University Berlin, Germany, \\ ${ }^{2}$ Institute of Pharmacology and Toxicology, University of Marburg, Germany, ${ }^{3}$ Department of Biochemistry and Cell Biology, \\ Faculty of Veterinary Medicine, Utrecht University, The Netherlands and ${ }^{4}$ Department of Internal Medicine and Endocrinology and \\ Department of Pathology, University of Tübingen, Germany \\ (Correspondence should be addressed to E Nieschlag, Institute of Reproductive Medicine of the University, Domagkstraße 11, D-48129 Münster, \\ Germany; Email: nieschl@uni-muenster.de)
}

\begin{abstract}
Background: Human chorionic gonadotropin/luteinizing hormone (hCG/LH) function in the male is mediated by the LH receptor (LHR) and is crucial for the normal development of internal and external genitalia. We report a 46 , XY patient who presented at the age of 16 with a female phenotype and delayed puberty. Gonads were located bilaterally in the inguinal canal, removed surgically and showed hypoplastic Leydig cells. Immunostaining for the LHR revealed that some Leydig cell progenitors were positive, while others were negative, reflecting different developmental stages of Leydig cell maturation.

Methods and Results: Molecular analysis of the LHR was performed on DNA extracted from blood samples of the patient, her parents and sister. The 11 exons of the LHR gene were amplified by PCR and subjected to further single stranded conformation polymorphism (SSCP) analysis. Aberrant migration patterns were observed in exon 7 . Upon sequencing, a homozygous $\mathrm{T}$ to $\mathrm{G}$ transversion was identified, resulting in a F194V substitution located in the extracellular domain. The parents and sister were heterozygous carriers of this mutation. Functional studies in transiently transfected COS-7 cells with the F194V LHR mutation showed the lack of cAMP production upon hCG stimulation, indicating complete inactivation of the receptor due to impaired trafficking of the receptor to the membrane. The mutation is located within a stretch of five amino acids Ala (A)-Phe (F)-Asn (N)-Gly (G)-Thr (T), highly conserved in glycoprotein hormone receptors. For the follicle-stimulating hormone (FSH) receptor (FSHR) loss-of-function mutations have been allocated to this region, a homozygous A189V mutation resulting in a resistant ovary syndrome and impaired spermatogenesis and a heterozygous N191I mutation with no apparent phenotype. Further mutational and functional analysis of the AFN region in the LHR and FSHR revealed that the integrity of this amino acid sequence is crucial for receptor function.
\end{abstract}

European Journal of Endocrinology 147 597-608

\section{Introduction}

Male sexual development in primates and humans comprises initial sex determination, followed by sexual differentiation into the male phenotype. While determination is mainly driven by SRY, the testis determining gene located on the $\mathrm{Y}$ chromosome, which induces the bipotential gonad to develop into a testis, differentiation is exclusively regulated by hormones. Male phenotypic development is under the control of anti-Müllerian hormone, causing Müllerian duct regression, and testosterone, essential for transformation and virilization of external genitalia (1). Fetal Leydig cell differentiation and testosterone production is stimulated by human chorionic gonadotropin (hCG) produced by the trophoblast and mediated by the hCG/luteinizing hormone (LH) receptor. After birth LH takes over the role of hCG to maintain testosterone production (2).

Aberrant hormone binding or signal transduction of hCG/LH through the LH receptor (LHR) directly affects androgen production, leading to disturbances of fetal as well as pubertal male development (3). The clinical 
phenotypes resulting from altered hCG/LH-LHR interaction in genetically male subjects range from male pseudohermaphroditism, characterized by female external phenotype with a blind ending vagina, lack of breast development and primary amenorrohea, to incomplete virilization of the external genitalia with micropenis and/or hypospadias $(1-3)$. In severe cases the responsiveness of Leydig cells to hCG is abolished, resulting in Leydig cell hypoplasia (LCH). Two types of $\mathrm{LCH}$ have been described (1). Type I LCH is the most severe form, resulting in a female phenotype and is caused by inactivating mutations in the LHR which completely prevent hCG/LH signal transduction and thus testosterone production. Patients with type II LCH are characterized by milder signs of androgen deficiency and are generally hypogonadal. This milder form is derived from mutations of the LHR, which only partially inactivate signal transduction and retain some responsiveness to hCG/LH (4).

Numerous activating mutations have been described for the LHR (5) but to date only a few inactivating mutations are known (2, 6-8). One possible explanation for this phenomenon could be that activating mutations are much more compatible with reproduction, e.g. females do not manifest any abnormal phenotype and males display signs of precocious puberty not affecting fertility, whereas inactivating mutations, besides their autosomal recessive inheritance, lead to infertility and will not be forwarded to the next generation. Mutations of the closely related follicle-stimulating hormone (FSH) receptor (FSHR) occur even less frequently: only one activating mutation has been described up to now, and only very few inactivating mutations of the FSHR causing

Table 1 Endocrine parameters. A, 5 months before gonadectomy; B, 22 months after gonadectomy, ethinyl estradiol replacement with $20 \mu \mathrm{g}$ daily, and thyroxine replacement with $75 \mu \mathrm{g}$ daily.

\begin{tabular}{lccc}
\hline Parameter & A & B & Normal range \\
\hline $\mathrm{FT}_{4}(\mathrm{ng} / \mathrm{dl})$ & 1.3 & 1.2 & $0.7-1.5$ \\
$\mathrm{TT}_{3}(\mathrm{ng} / \mathrm{ml})$ & 1.81 & 2.30 & $0.8-2.2$ \\
$\mathrm{TBG}(\mathrm{mg} / \mathrm{l})$ & 19 & 23 & $12-30$ \\
$\mathrm{TSH}\left(0^{\prime}\right)(\mathrm{mlU} / \mathrm{l})$ & 1.7 & 1.3 & $0.3-2.5$ \\
$\mathrm{TSH}\left(30^{\prime}\right)^{\star}(\mathrm{mlU} / \mathrm{l})$ & 11.9 & 10.9 & $5.0-22.5$ \\
$\mathrm{PRL}\left(0^{\prime}\right)(\mathrm{ng} / \mathrm{ml})$ & 22 & 34 & $5-20$ \\
$\mathrm{PRL}\left(30^{\prime}\right)^{\star}(\mathrm{ng} / \mathrm{ml})$ & 91 & 115 & $10-120$ \\
$\mathrm{GH}(\mathrm{ng} / \mathrm{ml})$ & 0.6 & 10.4 & $0.5-10.0$ \\
$\mathrm{IGF}-\mathrm{ng}(\mathrm{ng} /)$ & 313 & 171 & $90-500$ \\
$\mathrm{ACTH}(\mathrm{pg} / \mathrm{ml})$ & 27.7 & - & $10-50$ \\
$\mathrm{Cortisol}(\mu \mathrm{g} / \mathrm{dl})$ & 18.9 & - & $6.0-22.0$ \\
Transcortin $(\mathrm{mg} / \mathrm{l})$ & 5.2 & 9.2 & $3.0-8.5$ \\
Aldosterone $(\mathrm{pg} / \mathrm{ml})$ & 108 & - & $40-310$ \\
Renin activity $(\mathrm{ng} \mathrm{Angl} / \mathrm{ml} / \mathrm{h})$ & 2.03 & - & $0.15-2.12$ \\
Potassium $\left(\mathrm{K}^{+}\right)(\mathrm{mmol} / \mathrm{l})$ & 4.3 & 3.9 & $3.5-4.6$ \\
\hline
\end{tabular}

* 30 min after i.v. stimulation by $400 \mu \mathrm{g} \mathrm{TRH}$.

$\mathrm{FT}_{4}$, free thyroxine; $\mathrm{TT}_{3}$, total triiodothyronine; TBG, thyroid-binding globulin; PRL, prolactin; GH, growth hormone; IGF-I, insulin-like growth factor I; Angl, angiotensinogen type 1. gonadal dysgenesis, secondary amenorrhea, or impaired spermatogenesis have been identified (2, 9, 10). While activating mutations are located almost exclusively in the transmembrane domain, inactivating mutations or deletions are spread throughout N-terminus, C-terminus and transmembrane domains of the receptor. Overall, no putative hotspot for inactivating mutations has been discernible for the gonadotropin receptors.

In the present report, we describe the case of a patient with male pseudohermaphroditism caused by a homozygous inactivating $\mathrm{F} 194 \mathrm{~V}$ mutation of the LHR located in a highly conserved stretch of five amino acids of exon 7. Within this amino acid motif, inactivating mutations have been described for the closely related FSHR, underlining the crucial function of this motif for receptor functioning.

\section{Subject and methods}

\section{Case report}

A 16-year-old girl was referred to the Department of Internal Medicine and Endocrinology, University of Tübingen, Germany, because of delayed puberty, since her sister, younger by 1 year and 7 months experienced menarche at the age of 14 years. Both parents were immigrants from the same rural village of 800 inhabitants in the northern part of Greece. Close consanguinity is excluded, but not a distant relationship.

The phenotypic female of $55 \mathrm{~kg}$ was $171 \mathrm{~cm}$ tall with an upper/lower segment ratio of 0.84 . Breast development was infantile (Tanner stage I). Some sporadic pigmented terminal hairs were present in the pubic region (stage II), not so in the axillae. The external genitalia showed infantile labia majora et minora and a vaginal orifice (urogenital sinus) of $1 \mathrm{~cm}$ depth. There were no signs of virilization whatsoever. No dysplastic stigmata were detected; no goiter (sonotomographic volume $5 \mathrm{ml}$ ) and no clinical signs of overt hypothyroidism. Pigmentation was normal and homogeneous. In the inguinal canal tender testicle-like structures were palpable on both sides and measured $25 \times 10 \times 9 \mathrm{~mm}$ by sonography. No other structures of internal genitalia, such as derivatives of the Wolffian and Müllerian ducts, were discernible by ultrasound or magnetic resonance imaging (MRI).

Radiography of the left hand and wrist showed a bone age of 13 years by the Tanner method of maturity indicators. Magnetic resonance imaging of the brain was normal, especially with respect to the anterior and posterior pituitary, the stalk, pineal, optic chiasm, hypothalamic structures, and the septum pellucidum.

A normal male karyotype (46, XY) was detected. DNA sequencing revealed no indication of gene defects of the androgen receptor and the 5-alpha reductase 2 enzyme. Adrenocorticotropin (ACTH), cortisol, androstendione, dehydroepiandrosterone (DHEA) sulfate, 
Table 2 Time course of gonadal endocrine parameters before and after gonadectomy. Gonadectomy was performed in April 1998 (4/98).

\begin{tabular}{|c|c|c|c|c|c|c|c|c|}
\hline Parameter & $10 / 97$ & $11 / 97$ & $4 / 98$ & $7 / 98$ & $5 / 99$ & $2 / 00$ & Normal adult male & Normal adult female \\
\hline LH (IU/I) & $18 / 46^{*}$ & $17 / 43^{*}$ & $17 / 46^{*}$ & $29 / 153^{*}$ & $32 / 240 *$ & $37 / 322$ & $1.5-10.0$ & $1.5-10.0$ \\
\hline $\mathrm{FSH}(\mathrm{IU} / \mathrm{I})$ & $12 / 16^{\star}$ & $11 / 15^{*}$ & $65 / 86^{*}$ & $95 / 205^{\star}$ & $85 / 170^{*}$ & $39 / 111$ & $2.0-25.0$ & $2.0-25.0$ \\
\hline Estradiol (pg/ml) & 9 & 8 & 6 & $39(1)$ & $67(1)$ & $23(2)$ & $<50$ & $20-60$ \\
\hline Testosterone (ng/ml) & 0.17 & - & 0.22 & 0.13 & 0.13 & 0.18 & $3.0-8.0$ & $<0.60$ \\
\hline Androstenedione (ng/ml) & 1.34 & 1.44 & 1.18 & 0.91 & 0.91 & 1.32 & $1.20-2.50$ & $1.20-2.50$ \\
\hline DHEA sulfate $(\mathrm{ng} / \mathrm{ml})$ & 1930 & 1940 & 1690 & 1820 & 1350 & 1440 & $500-2500$ & $500-2500$ \\
\hline SHBG $(\mathrm{nmol} / \mathrm{l})$ & 66 & 74 & 58 & 92 & 71 & 101 & $15-50$ & $30-90$ \\
\hline
\end{tabular}

*Before and $30 \mathrm{~min}$ after i.v. stimulation by $100 \mu \mathrm{g} \mathrm{LH}-\mathrm{RH}$.

(1), Replacement by estradiol valerate $1 \mathrm{mg}$ and $2 \mathrm{mg}$ daily; (2), replacement by ethinyl estradiol $20 \mu \mathrm{g}$ daily.

SHBG, sex hormone binding globulin.

aldosterone, and renin activity were normal (Tables 1 and 2). Stimulation by hCG i.m. did not result in an increase in gonadal steroids after $72 \mathrm{~h}$ (Table 3). Furthermore, plasma concentrations of testosterone and estradiol were minimal, LH was increased and FSH was normal (Table 2).

Because of the high risk of neoplastic growth in dysontogenetic gonads, both inguinal gonads were removed by herniotomy. Macroscopically, they were normally differentiated small testicles with regular appendages and thready vasa deferentia. After gonadectomy the patient underwent estrogen replacement therapy, first estradiol valerate $1 \mathrm{mg}$ per day for 6 months, then $2 \mathrm{mg}$ for another 6 months, and afterwards $20 \mu \mathrm{g}$ ethinyl estradiol daily. Meanwhile, 22 months after gonadectomy, she developed breasts (Tanner stage III-IV) and pubic hair (stage IV). Her height increased to $178 \mathrm{~cm}$. Thyrotropin (TSH) levels rose to $2.7 \mathrm{mIU} / \mathrm{l}$ before and $22.9 \mathrm{mIU} / \mathrm{l}$ after thyrotropin releasing hormone (TRH) stimulation, indicating borderline primary hypothyroidism without detectable thyroid-specific autoantibodies. Therefore, the patient is treated intercurrently with $75 \mu \mathrm{g}$ thyroxine daily with subsequent normalization of TSH to $1.3 \mathrm{mIU} / \mathrm{l}$ before and $10.9 \mathrm{mIU} / \mathrm{l} 30 \mathrm{~min}$ after TRH stimulation (Table 1, column B). The slight hyperprolactinemia is monitored and considered functional, since a second MRI showed neither a pituitary adenoma nor any hypothalamic abnormality.

Table 3 hCG stimulation test with 5000 IU i.m.

\begin{tabular}{lcccc}
\hline Parameter & $\begin{array}{c}\mathbf{0 h} \\
\text { (basal) }\end{array}$ & $\mathbf{4 8 h}$ & $\mathbf{7 2 ~ \mathbf { ~ }}$ & $\begin{array}{c}\text { Normal } \\
\text { range }\end{array}$ \\
\hline Estradiol $(\mathrm{pg} / \mathrm{ml})$ & 7 & 9 & 7 & $1.5-2.5 \times *$ \\
Testosterone $(\mathrm{ng} / \mathrm{ml})$ & 0.27 & 0.27 & 0.25 & $1.5-2.5 \times{ }^{*}$ \\
Androstenedione $(\mathrm{ng} / \mathrm{ml})$ & 1.54 & 1.66 & 1.71 & - \\
DHEA sulfate $(\mathrm{ng} / \mathrm{ml})$ & 1520 & 1400 & 1260 & - \\
SHBG (nmol/l) & 88 & 79 & 84 & see Table 2 \\
\hline
\end{tabular}

* Normal response is an increase by 1.5 to 2.5 of the basal value at time 0 . SHBG, sex hormone binding globulin.

\section{DNA isolation and PCR analysis}

DNA was isolated from blood samples obtained from the patient as well as from her sister, father and mother. In addition, blood samples from a male volunteer with normal hormonal levels and normal sperm counts according to the WHO criteria were taken. Genomic DNA was purified using the Nucleon Kit (Herolab, Braunschweig, Germany). Exons $1-11$ of the LHR gene were amplified using the primers and cycling conditions described by Atger et al. (11). Each PCR sample $(25 \mu \mathrm{l})$ contained $10 \mathrm{nmol} / \mathrm{l}$ Tris $-\mathrm{HCl}(\mathrm{pH}$ 8.3), $50 \mathrm{nmol} / \mathrm{l} \mathrm{KCl,} 0.01 \%$ gelatin, $2 \mathrm{nmol} / \mathrm{l} \mathrm{MgCl}_{2}$, $0.2 \mathrm{mmol} / \mathrm{l}$ deoxy-NTPs, $2 \mathrm{U}$ Taq polymerase (Promega Corp., Heidelberg, Germany), $20 \mathrm{pmol} / \mathrm{l}$ primer, and $200 \mathrm{ng}$ DNA. The amplified products were subjected to $1-2 \%$ agarose gel electrophoresis for further analysis.

\section{Single stranded conformation polymorphism (SSCP) and in vitro mutagenesis}

The entire LHR gene consisting of 11 exons was screened for mutations either by direct sequencing (exon 11) or by SSCP gel electrophoresis. SSCP and sequence analysis were performed as described previously (12).

The human LH and FSH receptors cloned into the EcoRI restriction site of pSG5 (Stratagene, Heidelberg, Germany) were mutagenized by oligonucleotide-mediated site-directed mutagenesis using the Transformer site-directed mutagenesis kit (Clontech, ITC Biotechnology, Heidelberg, Germany). The selection primer (5'-GAGTGCAAAATGGGCGGTGTGAAAT$\left.3^{\prime}\right)$ converted the unique NdeI restriction site of pSG5 into NcoI. To introduce the different mutations (see Fig. 4) the following primers were used:

1. LHR-A193V 5'-GAAGTACAAAGTCATGTATTCAATGGGACGAC-3';

2. FSHR-A189V 5'-GAAATACACAACTGTGTATTCAATGGAACCCAA-3'; 
3. LHR-F194V 5'-GTACAAAGTCATGCAGTCAATGGGACGAC-3';

4. FSHR-F190V 5'-TACACAACTGTGCAGTCAATGGAACCCAAC- $3^{\prime}$;

5. LHR-N195I 5'-GAAGTACAAAGTCATGCATTCGGAAATGGGACGACACTGAC-3';

6. FSHR-N191I 5'- GAAATACACAACTGTGCATTCATTGGAACCCAACTA-3'.

The mutations were confirmed by direct PCR sequencing. Plasmids were isolated and purified by anion exchange columns (Qiagen, Hilden, Germany).

\section{Transfection of COS-7 cells and cAMP assays}

COS-7 cells were transiently transfected as described previously (13). Briefly, $5 \mu \mathrm{g} /$ well of plasmid DNA were transfected using a calcium-coprecipitation method. Cells were prelabeled with ${ }^{3}[\mathrm{H}]$ adenine (25-50 Ci/mmol, Dupont-NEN, Brussels, Belgium) and cAMP assays were performed 3 days after transfection. To measure cAMP accumulation, cells were stimulated for $1 \mathrm{~h}$ with $100 \mathrm{nmol} / \mathrm{l} \mathrm{hCG}$ (from urine of pregnant women, $3000 \mathrm{U} / \mathrm{mg}$, Sigma Chemical Co., St Louis, MO, USA) for wild-type (wt)-LHR and LHR mutants or $100 \mathrm{mU} / \mathrm{ml}$ porcine (p) FSH (Sigma) for wt-FSHR and FSHR mutants after washing the cells with serum-free DMEM containing $1 \mathrm{mmol} / \mathrm{l} 3$-isobutyl1-methylxanthine (Sigma). Termination of cAMP accumulation was performed by adding $1 \mathrm{ml} 5 \%$ trichloric acid, and the cAMP content of cell extracts was determined by cation exchange chromatography as described by Schöneberg et al. (13). For concentration response curves, cells were stimulated with different hormone concentrations. To account for experimental variability, wt-receptor cDNA was included as an internal control in each transfection assay and functional data were expressed as $\mathrm{x}$-fold increase of basal levels.

\section{${ }^{125}$ I-hCG displacement studies}

Binding experiments were performed as described by Schulz et al. (14). In brief, COS-7 cells were transiently transfected with either the wild-type LHR in the pSG5 vector or LHR F194V. Cells were harvested three days after transfection and membrane homogenates were used for displacement studies. Incubations were carried out for $90 \mathrm{~min}$ at room temperature in a $0.25-\mathrm{ml}$ volume. Each sample contained $0.1 \mathrm{nmol} / \mathrm{l}{ }^{125} \mathrm{I}-\mathrm{hCG}$ (4712 Ci/mmol, Dupont-NEN) and membranes of $2 \times 10^{5}$ cells. Concentrations of non-labeled hCG ran from $10^{-7}$ to $10^{-11} \mathrm{~mol} / \mathrm{l}$. Non-specific binding was defined as binding in the presence of $10^{-7} \mathrm{~mol} / \mathrm{l}$ hCG.

\section{Cell-surface ELISA}

Assessment of LHR cell surface expression was principally performed as described previously (15) To study cell surface expression of the LHR, an HA epitope tag was engineered in the N-terminus of the receptor between $\mathrm{Arg}^{26}$ and $\mathrm{Glu}^{27}$ to construct HA-LHR. An N-terminally tagged V2 vasopressin receptor, kindly provided by Torsten Schöneberg, Berlin, served as a control. COS-7 cells plated in 24-well-plates at $5 \times 10^{4}$ cells per well were transfected with either the wild-type HA-LHR in pSG5 or HA-LHR F194V. Three days after transfection cells were fixed (4\% formaldehyde in phosphate-buffered saline), and unspecific binding sites were blocked with DMEM/10\% FCS $\left(1 \mathrm{~h}, 37^{\circ} \mathrm{C}\right)$. Subsequently, cells were incubated at $37^{\circ} \mathrm{C}$ for $2 \mathrm{~h}$ with a peroxidase-labeled anti-HA-antibody (Roche Molecular Biochemicals). After removal of excess unbound antibody, $\mathrm{H}_{2} \mathrm{O}_{2}$ and $o$-phenylenediamine were added to serve as substrate and chromogen respectively. After $15 \mathrm{~min}$ the enzyme reaction was stopped by $1 \mathrm{~mol} / \mathrm{l} \mathrm{H}_{2} \mathrm{SO}_{4} / 0.05 \mathrm{~mol} / \mathrm{l} \quad \mathrm{Na}_{2} \mathrm{SO}_{3}$ and color development was measured at $450 \mathrm{~nm}$ using an ELISA reader (Bio-Tek Instruments).

\section{Immunohistochemistry}

After fixation in Bouin's solution the removed gonads were embedded in paraffin. The LH receptor monoclonal antibody P1B4 was a gift from Dr J Wimalasena (Department of Obstetrics and Gynecology, University of Tennesse, Knoxville, TN, USA). The antibody was raised against purified rat LH receptors, as described by Indrapichate et al. (16), and has been shown to bind to $\mathrm{LH}$ receptors in the human.

The immunostaining technique was performed on $5-\mu \mathrm{m}$ paraffin sections on silan-coated glass slides. The sections used in this study were obtained from the patient under investigation and a control patient with normal testicular morphology. Sections were deparaffinized and endogenous peroxidase was blocked with $1 \% \mathrm{H}_{2} \mathrm{O}_{2}$ in methanol for $30 \mathrm{~min}$. The slides were subsequently washed in $0.01 \mathrm{~mol} / \mathrm{l}$ Tris-bufferedsaline (TBS; pH 7.4), incubated with $0.1 \mathrm{~mol} / \mathrm{l}$ glycine in TBS for $30 \mathrm{~min}$ and rinsed with TBS. The slides were blocked with $10 \%$ normal goat serum for $30 \mathrm{~min}$ and then incubated overnight at $4{ }^{\circ} \mathrm{C}$ with the antibody against the $\mathrm{LH}$ receptor at a dilution of 1:5000 in TBS with $0.05 \%$ acetylated BSA (Aurion, Wageningen, The Netherlands). Following this incubation the slides were rinsed with TBS and then incubated for $60 \mathrm{~min}$ with a biotinylated goat-anti-mouse antibody (Vectastain Kit Elite, Vector Lab., Burlingame, CA, USA) diluted 1:200 in TBS containing 0.05\% acetylated BSA. Slides were again washed in TBS and subsequently incubated for at least $60 \mathrm{~min}$ with the components avidin (A) and biotin (B) of the ABC staining kit (Vector Lab). Both components (A and $B$ ) were 
diluted 1:2000 and prepared at least $15 \mathrm{~min}$ before addition to the sections. Slides were washed again in TBS and Tris-HCl $(0.05 \mathrm{~mol} / \mathrm{l}, \mathrm{pH} 7.6)$, and bound antibody was visualized using a $0.6 \mathrm{mg} / \mathrm{ml}$ solution of 3,3'-diaminobenzidine tetrachloride (Sigma Chemical Co.) in Tris- $\mathrm{HCl}$, to which $0.03 \% \mathrm{H}_{2} \mathrm{O}_{2}$ was added. All slides were subsequently counterstained with Mayers' hematoxylin.

Pilot experiments had previously demonstrated that the dilution of the LHR antibody used in this study gave optimal staining results. Control experiments were carried out and representative sections are shown in Fig. 3B and D. In these control experiments the primary antibody was either omitted from the procedure (not shown), or normal mouse serum was employed instead of the first antibody. Non-specific background staining was not observed.

\section{Results}

\section{Molecular analysis of the LHR gene}

Analysis of the LHR gene from the patient by SSCP revealed an aberrant migration pattern of exon 7 compared with two controls (Fig. 1). Sequencing of the total coding region including the adjacent splice sites of exon

\section{patient}

\section{control}

\section{control}

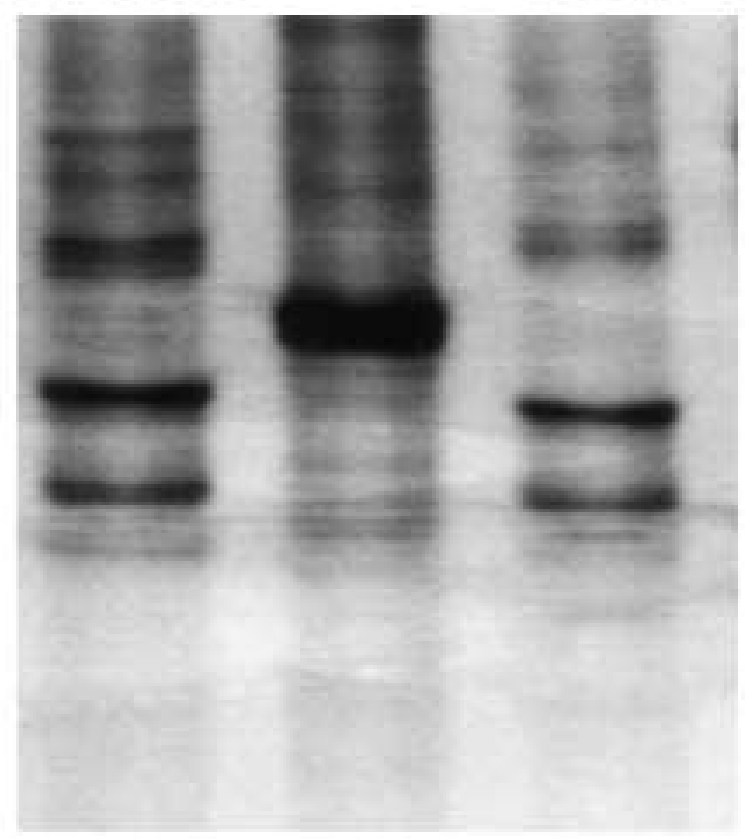

Figure 1 SSCP gel electrophoresis of exon 7. A 20\% polyacrylamide gel was run at $20^{\circ} \mathrm{C}$ for $4 \mathrm{~h}$ and the DNA fragments were visualized by silver staining.
7 showed a homozygous mutation at nucleotide position 580, leading to a $\mathrm{T}$ to $\mathrm{G}$ transversion. The mutation was located in the extracellular domain of the LHR and caused an amino acid change from F194 to V. The observed nucleotide change eliminates a restriction site for BsmI, which was used further to screen the family members for the presence of this mutation. In the presence of the BsmI restriction site the DNA fragment (194 bp) can be cut, resulting in a $118 \mathrm{bp}$ and a $76 \mathrm{bp}$ fragment. As shown in Fig. 2, father, mother and sister are heterozygous carriers, whereas the proposita is homozygous for the T580G mutation.

\section{Immunohistochemistry for the LHR in the testis of the patient}

Sections of the gonads displayed testicular tubules with abundant Sertoli cells, some resting spermatogonia, and interstitially some sparse cells reminiscent of fibroblast-like Leydig cell precursors and hypoplastic fetal Leydig cells. Since LH is essential for the development of the adult-type Leydig cell population, no mature LHR positive adult-type Leydig cells were observed. Immunohistochemistry using a monoclonal antibody raised against purified LHR showed intense staining in the hypoplastic Leydig cells and fibroblastlike cells, while other cells with a fibroblast-like morphology seemed to lack LHR protein expression and were immuno-negative (Fig. 3).

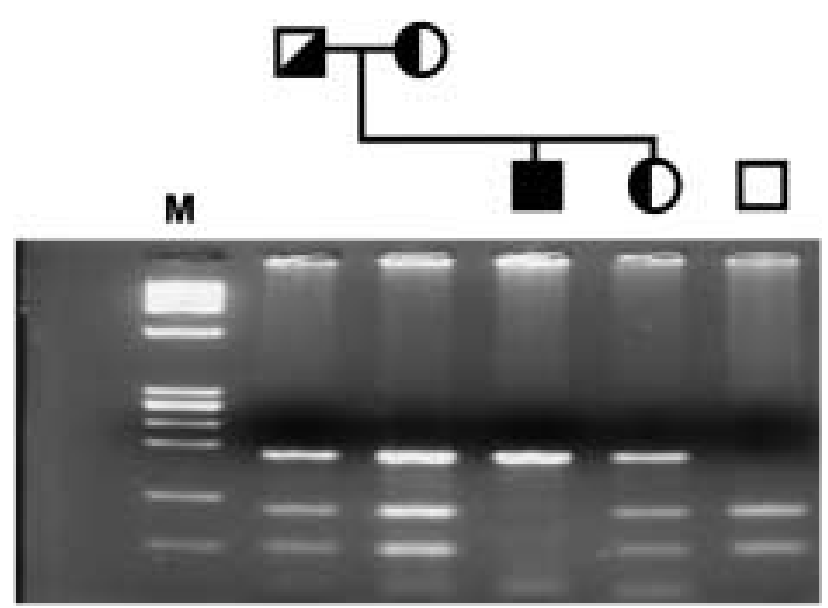

Figure 2 Amplification of exon 7 of the LHR gene. Samples of genomic DNA were obtained from the patient (filled square), the mother (half-filled circle), father (half-filled square) and sister (half-filled circle). Exon 7, including adjacent $5^{\prime}$ - and $3^{\prime}$ sequences, was amplified (194 bp) and digested with the restriction enzyme Bsml, capable of cutting the wt-LHR sequence $5^{\prime}$-TGCATTC- $3^{\prime}$, which results in the generation of two fragments (128 bp and $76 \mathrm{bp}$, control, square). The mutation T580G abolishes the restriction site. The pedigree above indicates the heterozygous status of the father, mother, and sister (half-filled symbols), whereas the patient is homozygous for this mutation. Lane M, DNA molecular weight marker (Hae III). 


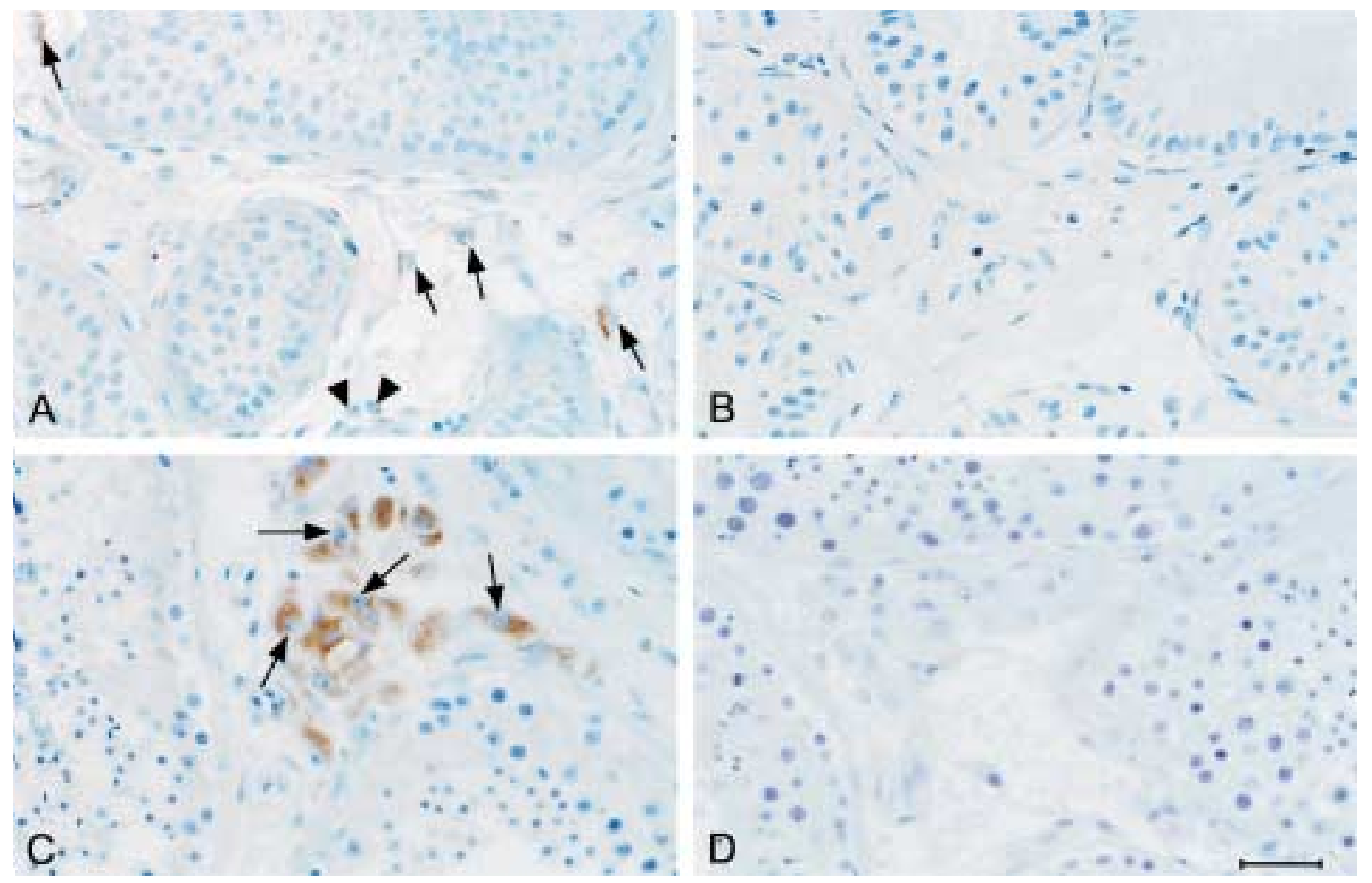

Figure 3 Immunohistochemical localization of the LHR in the testis of the patient with the LHR mutation (A) and in a normal control patient (C) using a monoclonal antibody. As a control the first antibody was replaced by normal mouse serum, demonstrating the specificity of the staining (B and $D$ ). Histological examination reveals immature seminiferous tubules with abundant Sertoli cells, some resting spermatogonia, and LHR-positive hypoplastic fetal Leydig cells and Leydig cell progenitors having a more fibroblast-like morphology (arrows, A). Fibroblast-like cells that do not stain positively with the LHR antibody are indicated by arrowheads. Normal mature Leydig cells show intense staining for the LHR protein (C). Bar represents $26 \mu \mathrm{m}$.

\section{Functional studies}

The observed mutation is located in a stretch of five amino acids, consisting of Ala (A)- Phe (F)- Asn (N)Gly (G)-Thr (T), completely conserved within the glycoprotein hormone receptors and among all mammalian species. Since naturally occuring mutations within this motif have already been described for the FSHR, we designed a mutational analysis approach based on known mutations to elucidate the importance of the A-F-N-G-T motif for LHR and FSHR function.

According to the previously described two mutations in the FSHR (8) and the identified mutation in the LHR (this manuscript), the following amino acid changes were introduced into the FSHR: A189 was replaced by V, F190 by $\mathrm{V}$ and N191 was replaced by I. In parallel, the LHR was mutated, whereby A193 was replaced by V, F194 by V and N195 was replaced by I (Fig. 4).

Transfection of COS-7 cells with the different receptor constructs and subsequent stimulation with hCG $(100 \mathrm{nmol} / \mathrm{l})$ and $\mathrm{pFSH}(100 \mathrm{mU} / \mathrm{ml})$ resulted in a robust increase in cAMP production mediated by the wt-LHR and wt-FSHR respectively (Fig. 5). The mutation identified in our patient, F194V for the LHR and the F190V mutation in the FSHR dramatically decreased cAMP production (Fig. 6A). The previously described inactivating mutation of the FSHR A189V (2) displayed only a weak cAMP accumulation upon stimulation with pFSH. Similarly, the corresponding LHR mutation A193V led to a reduced maximum cAMP level as compared with the wt-LHR receptor when stimulated with hCG. Mutation of the putative glycosylation site N195I in the LHR and N191I in the FSHR resulted in a reduced cAMP production for both receptors, but was more obvious for the FSHR.

To characterize the mutant receptors in more detail, concentration response curves were obtained for receptor constructs which gave a maximum stimulation of more than twofold over basal levels. For LHR mutants (Fig. 5B) the $\mathrm{EC}_{50}$ value for N195I $(0.13 \mathrm{nmol} / \mathrm{l})$ was reduced by a factor of 7 as compared with the wt-LHR receptor $(0.91 \mathrm{nmol} / \mathrm{l})$ and A193V $(0.98 \mathrm{nmol} / \mathrm{l})$. As shown in Fig. 5D, no major differences 

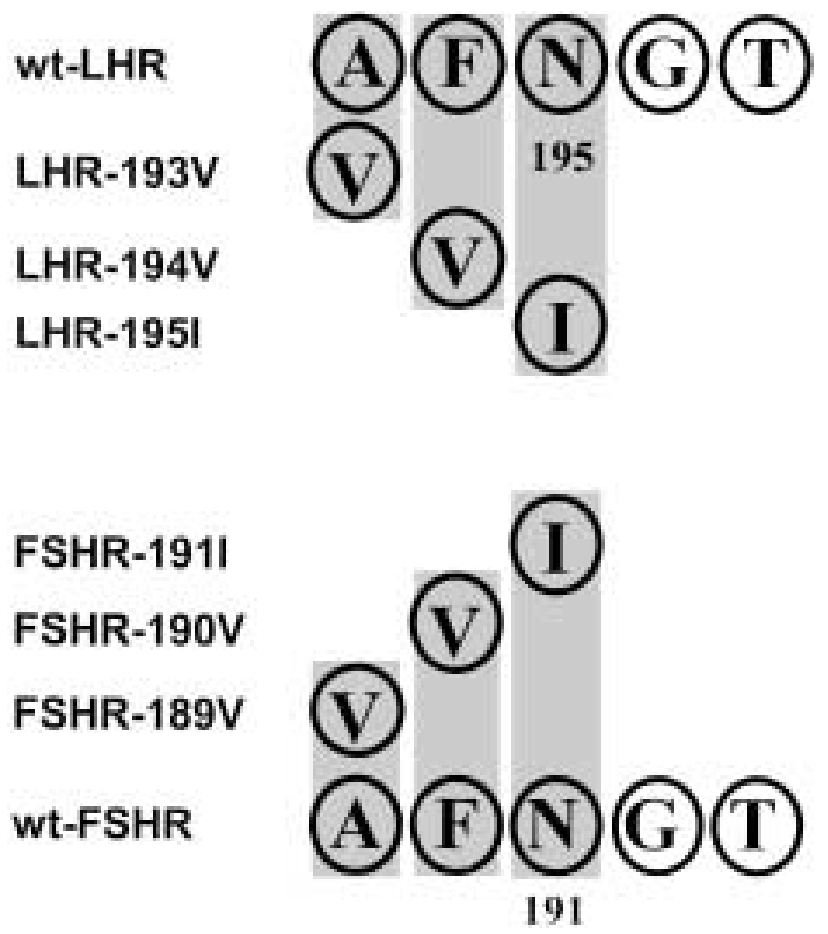

Figure 4 Schematic representation of the Ala(A)-Phe(F)-Asn(N)Gly(G)-Thr(T) motif located within exon 7 of the LHR (upper line) and FSHR (bottom line). The amino acid changes being introduced by in vitro mutagenesis are indicated. Numbering is according to the location of Asn which is position 195 in the case of the LHR and 191 for the FSHR. Additionally G was inserted between $\mathrm{F}$ and $\mathrm{N}$ to mimic the amino acid sequence in a recently described LGR.

in the $\mathrm{EC}_{50}$ values for the $\mathrm{FSHR}$ constructs were observed (wt-FSHR: $1.36 \mathrm{mU} / \mathrm{ml}$; N191I: $3.0 \mathrm{mU} / \mathrm{ml}$ ).

The identified F194V mutation in the LHR was studied further by performing dose-dependency experiments in which the wt or the mutated LHR were stimulated with increasing concentrations of hCG. Stimulation with $10^{-7} \mathrm{~mol} / \mathrm{l}$ hCG could evoke a nearly 25-fold increase in cAMP production in the wt-LHR over the basal levels whereas stimulation of the mutated receptor did not result in cAMP values significantly different from basal (Fig. 6A). Thus, the mutation completely inactivates signal transduction of the LHR. In order to investigate whether this impaired signal transduction is due to an effect on the signal transduction machinery or on the hormone binding capacity of the recpetor we performed displacement experiments and studied the receptor expression at the membrane.

Using membranes prepared from identical numbers of cells transiently transfected either with wt-LHR cDNA or LHR-F194V cDNA, we observed specific binding of ${ }^{125} \mathrm{I}-\mathrm{hCG}$ which could be displaced by increasing amounts of unlabeled hCG. The $\mathrm{IC}_{50}$ values were 0.44 and $0.25 \mathrm{nmol} / \mathrm{l}$ for wt-LHR and LHR-F194V respectively. These observations show that the ligand-binding domain of the mutated LHR is correctly folded and binds hCG with an affinity comparable with that of the wt-LHR (Fig. 6B). Thus, impaired ligand-binding to the receptor cannot account for the severe functional defect of LHR-F194V.

Measuring the surface expression of the wt- and the mutated LHR by a cell surface ELISA, using the expression of the vasopression receptor as an internal control $(100 \%)$, revealed values of $10.1 \pm 0.8 \%$ for the wt-LHR and $1.2 \pm 1.0 \%$ for the F194V LHR $(n=2)$. The data indicate that the mutated receptor when compared with the wt-LHR is presumably not expressed at all at the cell surface and that it remains completely cytosolic or stacked to inner cell membranes like the endoplasmic reticulum.

\section{Discussion}

\section{Patient}

The described patient displayed the full phenotype of Leydig cell hypoplasia (LCH) type I, characterized by a blind-ending vagina, lack of breast development and $\mathrm{XY}$ karyotype. This severe form of LCH indicates the complete absence of $\mathrm{hCG} / \mathrm{LH}$ signal transduction in Leydig cells, which is also evident by the extremely low testosterone and estradiol levels in the presence of elevated levels of LH and normal FSH (Table 2). Testosterone, androstendione, and estradiol could not be increased by hCG stimulation (Table 3). However, in patients with LCH type II, caused by partially inactivating mutations of the LHR, hCG stimulation results in a slight but consistent increase in testosterone serum levels (4). This residual activity of the LHR seems to enable some degree of androgenization, resulting in a variable phenotypic picture ranging from individuals with ambiguous genitalia to male hypogonadism (2, 4). The functional studies on the F $194 \mathrm{~V}$ mutation in our patient are in full accordance with the observed clinical phenotype of LCH type I (1). Stimulation of COS-7 cells transiently transfected with the mutated receptor cDNA construct with $100 \mathrm{nmol} / \mathrm{l} \mathrm{hCG}$ could not evoke any increase in cAMP production, thus indicating complete inactivation of the LHR (Figs 5 and 6). Thus the homozygous F194V mutation is the cause of the observed male pseudohermaphroditism in this patient. Father, mother and sister of the proposita are heterozygous carriers of this mutation, but do not show any phenotypical signs of an impaired LH/LHR interaction (Fig. 2). It is generally believed that heterozygous mutations within the gonadotropin receptors do not display any specific phenotype, since the normal allele can compensate for the loss-of-function mutation of the corresponding allele. Up to now there are no gene dose effects or preferential expression of one of the alleles described which could lead to a decreased LHR expression causing milder forms of hypovirilization or subtle signs of female infertility. However, homozygous 
A

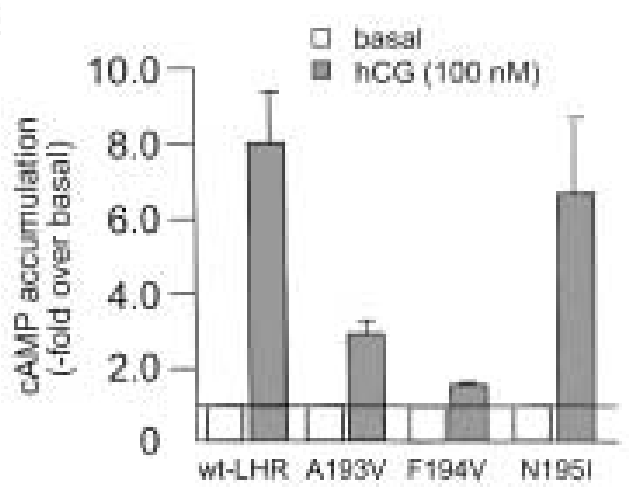

C

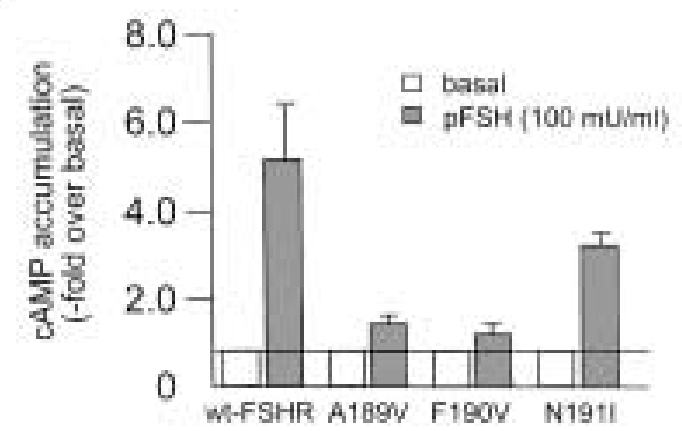

B

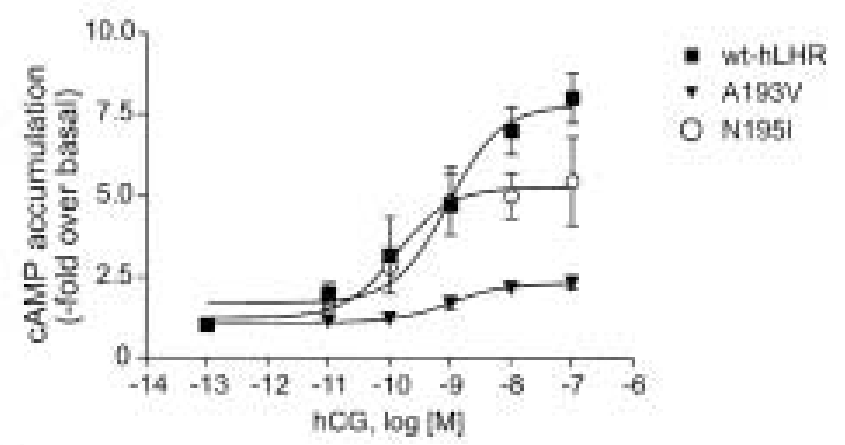

D

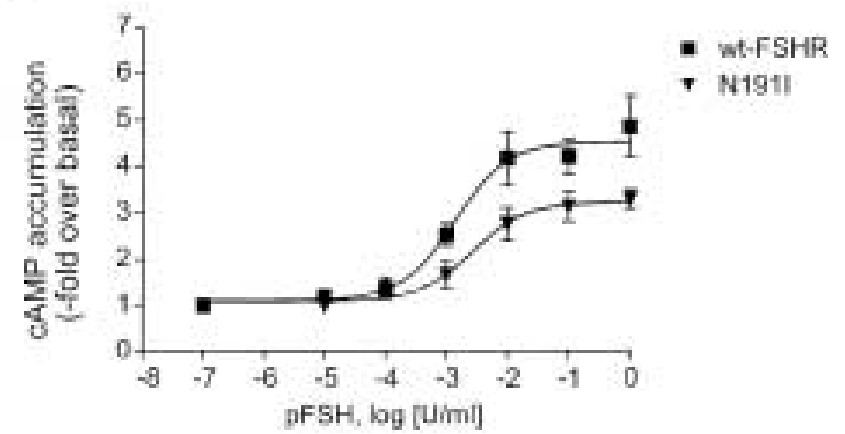

Figure 5 Functional analysis of LHR and FSHR mutants. To characterize mutant LH and FSH receptors, COS-7 cells were transfected with the different constructs. CAMP accumulation assays were perfomed as described under Subject and methods. Basal (open bars) and agonist-induced cAMP levels (shaded bars) ( $A$ and $C$ ) are presented as means of three to five independent experiments, each carried out in triplicate. For concentration response curves (B and $D)$ transfected cells were stimulated with increasing concentrations of hCG (for LHR constructs) or pFSH (for FSHR constructs). The data are presented as means (-fold over basal) of two to four independent experiments, each carried out in duplicate.

inactivating mutations of the LHR in females (46, XX) usually in some sisters of $\mathrm{LCH}$ cases, result in subclinical estrogen deficiency. These cases show normal development of external and internal female genitalia, maturation of primary and secondary sexual characteristics, but primary amenorrhea with occasional irregular spotting, infertility by anovulation, cystic ovaries, and osteopenia (17). The increase in FSH observed in the patient soon after gonadectomy (Table 2) reflects the ablation of the non-steroidal inhibitory function of the Sertoli cells mediated by inhibin. The persistent doubling of basal LH serum levels shows incomplete suppression by pure estrogen treatment. The hyperprolactinemia is in accordance with similar observations in patients undergoing male-to-female transsexual conversion under estrogen treatment after orchidectomy (18).

Until recently the clinical phenotype of LCH type I was suspected to be exclusively due to genetic alterations in the LHR gene. However, in 1999 Zenteno et al. (19) described a family with characteristic clinical symptoms of LCH, but were unable to identify any mutation or deletion in the LHR gene of affected family members. This might indicate defects in other loci presumably involved in Leydig cell differentiation, thus making LCH a genetically heterogeneous condition. In addition to these findings, mutations of or deletions in the LHR do not always give rise to inactivated or activated receptors. We have recently identified a patient in whom a homozygous deletion of exon 10 of the LHR did not cause inactivation of the receptor, but led to a receptor isoform capable of discriminating between $\mathrm{LH}$ and hCG action and responding only to hCG but not to LH. This patient displayed regular male sexual differentiation (due to intrauterine hCG action) but failed to enter puberty (20).

Histological examination of the testis from our patient revealed that the seminiferous tubules consist of Sertoli cells and some spermatogonia, indicative of the complete absence of spermatogenesis. This spermatogenic failure is caused by the lack of testosterone action during embryonic development, also crucial for testicular descent and later, during adulthood, for stimulation of spermatogenesis (21). Immunohistochemical staining of the testis using a monoclonal LHR antibody showed distinct positive staining in some of the interstitial cells. Fetal Leydig cell differentiation is a multistep process, during which 
A

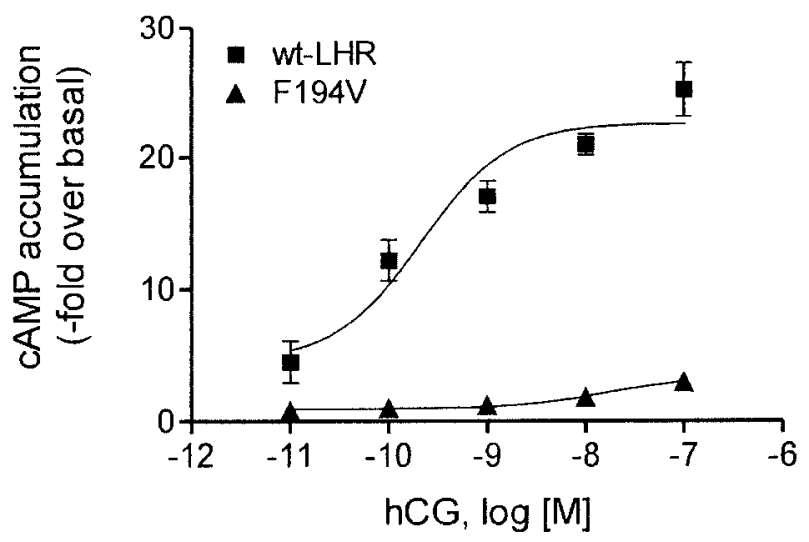

B

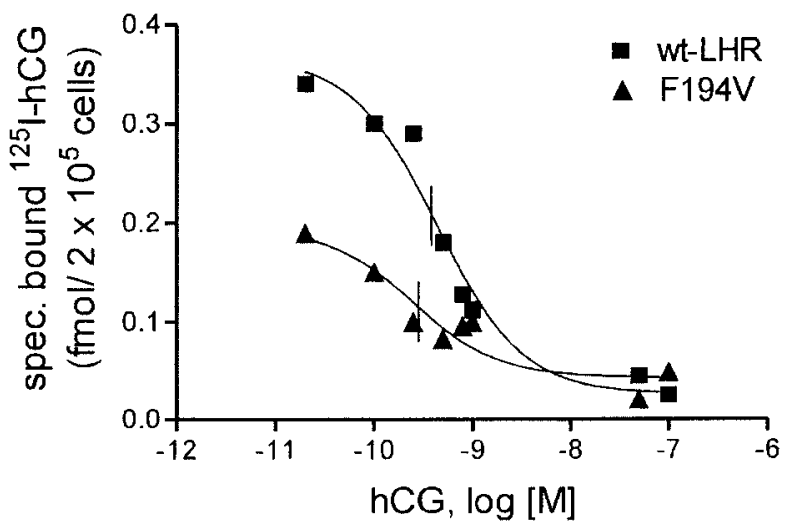

Figure 6 Analysis of cAMP production and ${ }^{125}$ I-hCG binding by LHR-F194V. (A) cAMP accumulation assays were performed in COS-7 cells transiently transfected with expression constructs coding for the wild-type LHR ( $\boldsymbol{\square})$ and LHR-F194V (A). Cells were incubated with increasing concentrations of hCG, and CAMP accumulation was determined as described in Subject and methods. Data are presented as means (-fold over basal) \pm S.E.M. of three independent experiments each performed in triplicate. (B) ${ }^{125}$ I-hCG displacement experiments were performed using membranes of COS-7 cells transiently transfected with constructs coding for the wild-type LHR ( $\boldsymbol{\square})$ and LHR-F194V ( $\boldsymbol{\Delta})$. Membranes were incubated with $0.1 \mathrm{nmol} / \mathrm{I}^{125} \mathrm{I}-\mathrm{hCG}$ and increasing concentrations of non-labeled hCG as described in Subject and methods. Data are presented as means of two independent experiments each performed in duplicate.

undifferentiated mesenchymal cells initially acquire the steroidogenic machinery by an unknown mechanism. With the expression of the LHR and the secretion of hCG, maturation of fetal-type Leydig cells starts, associated with increased steroidogenesis (22). The development of the adult-type Leydig cell population depends strongly on LH and functioning LHRs. Thus the resistance to LH action caused by a non-functional
LHR prevents the development of mature and functioning Leydig cells and is reflected by the nondifferentiated morphology and the sparse LHR immunostaining of the Leydig cell progenitors observed in the testis of the patient.

In rodents male sexual differentiation is also strictly dependent on testosterone; however, since CG is lacking in lower mammalian species, a testicular paracrine regulation of testosterone biosynthesis in Leydig cells is assumed to play a pivotal role. Thus elimination of the LHR in knock-out mice (LuRKO-mice) at birth yields phenotypically normal male mice with testes and genital structures indistinguishable from their wild-type littermates $(23,24)$. Postnatally, sexual maturation, e.g. spermatogenesis and accessory sex organ maturation is blocked by the lack of testosterone, which then is purely LH-dependent. In part, this mouse model resembles the pathogenesis of Leydig cell hypoplasia caused by inactivating LHR mutations.

\section{The potential role of the AFNGT motif}

Within the extracellular domain the glycoprotein hormone receptors, LHR, FSHR and TSHR, share some characteristic motifs. The most prominent ones are the leucine-rich repeats, consisting of approximately 24 amino acids, spread throughout the whole extracellular domain $(10,24,25)$. They are believed to form a horseshoe-shaped extracellular domain essential for ligand binding. Recently, it has been shown that the leucine-rich repeats are also present in other G-protein-coupled receptors identified in human and other species such as the fruitfly and sea anemone (26). These receptors bear a variable number of leucine-rich repeats, but their ligands are still unknown. Phylogenetic studies revealed that there are three subclasses of leucine-rich repeats containing G-protein-coupled receptors present; the TSHR, FSHR and LHR belong to one subclass of these receptors (26). While leucine-rich repeats are a hallmark for this type of receptor other conserved elements within the extracellular domain are difficult to identify. One common element which can be allocated within all three glycoprotein hormone receptors is the AFNGT motif, a stretch of five amino acids, completely conserved in the TSHR, FSHR and LHR and among different species (10).

Interestingly, the AFNGT motif, in part, contains a putative glycosylation signal site $(\mathrm{NXS} / \mathrm{T})$, whereas no function can be allocated to the two other amino acids ( $\mathrm{A}$ and $\mathrm{F}$ ). For the FSHR two mutations in this motif have been described in patients (10). One changes A189 into V, thereby leading to an almost complete inactivation of the receptor. Clinically, this inactivating mutation has been characterized on the female side by an FSH-resistant ovary and on the male side by impaired spermatogenesis. Extensive functional studies on this mutation revealed that the FSHR A189V 
mutation has normal binding affinity but significantly reduced plasma membrane expression and signal transduction. Using confocal microscopy most FSHR immunoreactivity in cells transfected with the mutated cDNA appeared to be sequestered within the cells indicating a possible function of the AFNGT motif in receptor folding (27-30). The second FSHR described mutation within this motif led to the transition from N191 to I. Since the patient in whom this mutation was identified was a heterozygous carrier, no phenotype was described. Functional studies with this mutated FSHR in transiently transfected COS-7 cells revealed a decrease in cAMP production when compared with the wt-FSHR upon FSH stimulation (9).

The AFNGT motif is also present in the two recently identified human leucine-rich repeats containing G-protein-coupled receptors (LGR 4 and 5) (26); however, it is interrupted by the insertion of a $\mathrm{G}$ or $\mathrm{T}$ residue, giving rise to an $\mathrm{AF}(\mathrm{G} / \mathrm{T}) \mathrm{NGT}$ motif.

In our experimental approach we characterized the consequences of mutations within the AFNGT motif on signal transduction. For this purpose we have introduced into the FSHR and the LHR cDNA all previously described mutations in patients for the AFNGT motif. The functional studies revealed that the F194V LHR mutation identified in our patient almost completely inactivates the LHR and also the equivalently mutated FSHR (Figs 5 and 6). These findings were confirmed by the dose-dependency experiments. Displacement experiments revealed that binding per se was not grossly affected, but trafficking of the receptor protein to the cell membrane was impaired. Thus trapping of the receptor within the cell compartments seems to be the major mechanism for the observed inactivation of the F194V LHR.

The A189V mutation, originally described for the FSHR, displayed the expected reduction in cAMP production and the same mutation in the LHR A193V also markedly decreased cAMP production; however, some residual activity can be observed. This is in agreement with a recent study in which the effects of the A189V of the FSHR were studied in more detail. The mutation leads to an intracellular sequestration of most of the mutated protein. The remaining low amounts of receptor protein which are transported to the cell surface are capable of ligand binding and cAMP response, albeit at a strongly reduced level (27-fold for the wt versus 8-fold for the mutated FSHR) (30). Additional experiments mutating the corresponding amino acid in the LHR yielded similar results and are in agreement with our findings of markedly reduced, but not absent capacity of signal transduction. Changing the putative glycosylation site N191 to I, as has been described for a FSHR mutation, led to a reduction in cAMP production compared with wt-FSHR. Similar results were observed for the corresponding mutation in the LHR.
Segaloff and colleagues (31) have demonstrated the role of the putative glycosylation motif (NXS/T) within the AFNGT amino acid stretch for LHR and FSHR expression and function. In the rat FSHR an N192A mutation does not lead to inactivation of the receptor; instead, the mutated receptor displays somewhat reduced human FSH binding which is caused by a lower number of receptors being expressed at the plasma membrane. This is in full agreement with our data on the FSHR N191I mutant, in which the stimulation by pFSH could evoke a significant increase in cAMP production.

While in the FSHR at least one site has to be glycosylated to maintain receptor function, the LHR seems to be more flexible with respect to the extent of glycosylation, and N-linked carbohydrates do not seem to be essential for receptor function per se. For example, mutation of N193 to Q in the rat FSHR severely affects receptor integration in the plasma membrane. In subsequent experiments the adjacent T195 was mutated to A, thus removing the glycosylation motif site; however, this mutation did not have any effect on receptor function. This implies that glycosylation at position N193 is not crucial for receptor function, although the kind of amino acid at this position might be of importance. In our case we have introduced isoleucine (I) at position 193, a mutation previously described in a patient. Isoleucine is hydrophobic, whereas $Q$ is a more polar residue. These different biochemical characteristics of I and Q might explain why we could observe a clear increase in cAMP production in the mutated 193I LHR upon hCG stimulation.

Concerning the mechanisms by which mutations at glycosylation sites might influence receptor function, Segaloff and colleagues $(31,32)$ demonstrated that glycosylations per se are not necessarily required for hormone binding; however, they are crucially involved in folding of the nascent receptor protein into a conformation compatible with hormone binding. This applies more to the FSHR than to the LHR.

Collectively, these experiments demonstrate that the AFNGT motif is crucial for gonadotropin receptor function. Mutations in this region presumably influence receptor folding, which in turn affects receptor trafficking to the cell membrane. This assumption is also evident from studies showing that the A189V mutation in the FSH and A193V in the LHR leads to intracellular sequestering of the receptor, indicative of an impaired membrane integration $(2,29,30)$. Assuming that such a change affects receptor folding/trafficking, the LGR-type receptors might have a different threedimensional structure of the extracellular domain compared with the LHR and FSHR, where changes in this motif affect receptor folding.

In the LHR and FSHR the overall frequency of mutations is low $(2,10,28,33)$; in the case of the FSHR only two other compound heterozygous mutations, aside from the mutations in the AFNGT 
motif, have been reported and for the LHR approximately 15 mutations have been described so far. The identification of an inactivating mutation in the AFNGT motif in exon 7 of the LHR (this report), together with the previously described mutations in this region for the FSHR, points to the crucial function of this motif and makes exon 7 a prime candidate to start with when screening glycoprotein hormone receptors for mutations.

\section{Acknowledgements}

The authors gratefully acknowledge the diagnostic and therapeutic contributions of Dr O Hiort, Department of Pediatrics, University of Lübeck; Prof. P Kaiser and Dr U Klein-Vogler, Department of Clinical Genetics; Prof. R Teichmann, Department of Surgery; Dr E Neeser and Dr M Zwirner, Department of Gynecology and Obstetrics, all from the University of Tübingen. We further want to thank L Pekel and $\mathrm{M}$ de Boer-Brouwer for excellent technical assistance and S Nieschlag, MA, for language editing. This study was supported by grants from the Deutsche Forschungsgemeinschaft (Confocal Resarch Group 'The male gamete: production, maturation, function' $\mathrm{Ni} 130-15$ and GR1547/2-1).

\section{References}

1 Themmen APN, Martens JWM \& Brunner HG. Activating and inactivating mutations in LH receptors. Molecular and Cellular Endocrinology $1998 \mathbf{1 4 5} 137-142$.

2 Huhtaniemi I. Ontogeny of the luteinizing hormone action in the male. In The Leydig Cell, pp 365-382. Eds AH Payne, MP Hardy \& LD Russel. Vienna, Illinois, USA: Cache River Press, 1996.

3 Huhtaniemi I. Mutations of gonadotrophin and gonadotrophin receptor genes: what do they teach us about reproductive physiology? Journal of Reproduction and Fertility 2000119 173-186.

4 Martens JWM, Verhoef-Post M, Abelin N, Ezabella M, Toledo SPA, Brunner HG \& Themmen APN. A homozygous mutation in the luteinizing hormone receptor causes partial Leydig cell hypoplasia: correlation between receptor activity and phenotype. Molecular Endocrinology 199812 775-784.

5 Nordhoff V, Gromoll J \& Simoni M. Constitutively active mutations of G-protein-coupled receptors: the case of the human luteinizing hormone and follicle-stimulating hormone receptors. Archives of Medical Research $199930501-509$.

6 Wu SM, Werber E, Rennert OM \& Chan WY. Luteinizing hormone receptor mutations in disorders of cancer. Frontiers in Biosciences 20005 343-352.

7 Beck-Peccoz P, Romoli R \& Persani L. Mutations of LH and FSH receptors. Journal of Endocrinological Investigation $2000 \mathbf{2 3}$ 566-572.

8 De Roux N \& Milgrom E. Inherited disorders of GnRH and gonadotropin receptors. Molecular and Cellular Endocrinology $2001 \mathbf{1 7 9}$ 83-87.

9 Gromoll J, Simoni M \& Nieschlag E. An activating mutation of the follicle-stimulating hormone receptor autonomously sustains spermatogenesis in a hypophysectomized man. Journal of Clinical Endocrinology and Metabolism 199681 1367-1370.
10 Simoni M, Gromoll J \& Nieschlag E. The follicle-stimulating hormone receptor: biochemistry, molecular biology, physiology and pathophysiology. Endocrine Reviews 199718 739-773.

11 Atger M, Misrahi M, Sar S, LeFlem A, Dessen P \& Milgrom E. Structure of the human luteinizing hormone choriogonadotropin receptor gene: unusual promoter and $5^{\prime}$ non-coding regions. Molecular and Cellular Endocrinology 1995111 113-123.

12 Gromoll J, Bröcker M, Derwahl M \& Höppner W. Detection of mutations in glycoprotein hormone receptor. Methods 200021 $83-97$.

13 Schöneberg T, Yun J, Wenkert D \& Wess J. Functional rescue of mutant V2 vasopressin receptors causing nephrogenic diabetes insipidus by a co-expressed receptor polypeptide. EMBO Journal $1996151283-1291$.

14 Schulz A, Schöneberg T, Paschke R, Schultz G \& Gudermann T. Role of the third intracellular loop for the activation of gonadotropin receptors. Molecular Endocrinology 199913 181-190.

15 Biebermann H, Schöneberg T, Schulz A, Krause G, Grüters A, Schultz G \& Gudermann T. A conserved tyrosine residue $(\mathrm{Y} 601 \mathrm{H})$ in transmembrane domain 5 of the human thyrotropin receptor serves as a molecular switch to determine G-protein coupling. FASEB Journal 199812 1461-1471.

16 Indrapichate K, Meehan D, Lane TA, Chu SY, Rao ChV, Johnson D, Chen TT \& Wimalasena J. Biological actions of monoclonal luteinizing hormone/human chorionic gonadotropin receptor antibodies. Biology of Reproduction $1992 \mathbf{4 6}$ 265-278.

17 Toledo SP, Brunner HG, Kraaij R, Post M, Dahia PL, Hayashida CY, Kremer H \& Themmen AP. An inactivating mutation of the luteinizing hormone receptor causes amenorrhea in a 46,XX female. Journal of Clinical Endocrinology and Metabolism 11 3850-3854.

18 Serri O, Noiseux D, Robert F \& Hardy J. Lactotroph hyperplasia in an estrogen treated male-to-female transsexual patient. Clinical case seminar. Journal of Clinical Endocrinology and Metabolism $1996813177-3179$.

19 Zenteno JC, Canto P, Kofman-Alfaro S \& Mendez JP. Evidence for genetic heterogeneity in male pseudohermaphroditism due to Leydig cell hypoplasia. Journal of Clinical Endocrinology and Metabolism $1999 \mathbf{8 4} 3803-3806$.

20 Gromoll J, Eiholzer U, Nieschlag E \& Simoni M. Male hypogonadism caused by homozygous deletion of exon 10 of the luteinizing $(\mathrm{LH})$ receptor: differential action of human chorionic gonadotropin and LH. Journal of Clinical Endocrinology and Metabolism 200085 2281-2286.

21 Nieschlag E, Simoni M, Gromoll J \& Weinbauer GF. Role of FSH in the regulation of spermatogenesis: clinical aspects. Clinical Endocrinology 199951 139-146.

22 Misrahi M, Meduri G, Pissard S, Bouvattier C, Beau I, Loosfelt H, Jolivet A, Rappaport R, Milgrom E \& Bougneres P. Comparison of immunocytochemical and molecular features with the phenotype in a case of incomplete male pseudohermaphroditism associated with a mutation of the luteinizing hormone receptor. Journal of Clinical Endocrinology and Metabolism 199782 2159-2165.

23 Zhang FP, Poutanen M, Wilbertz J \& Huhtaniemi I. Normal prenatal but arrested postnatal sexual development of luteinizing hormone receptor knockout (LuRKO) mice. Molecular Endocrinology $200115172-183$.

24 Lei ZM, Mishra S, Zou W, Xu B, Foltz M, Li X \& Rao Ch R. Targeted disruption of luteinizing hormone/human chorionic gonadotropin receptor gene. Molecular Endocrinology 200115 184-200.

25 Ascoli M, Fanelli F \& Segaloff DL. The lutropin/choriogonadotropin receptor, a 2002 perspective. Endocrine Reviews 200223 $141-174$.

26 Hsu S, Kudo M, Chen T, Nakabayashi K, Bhalla A, van der Spek PJ, van Duin M \& Hsueh AJW. The three subfamilies of leucinerich repeat-containing $\mathrm{G}$ protein-coupled receptors (LGR): identification of LGR6 and LGR7 and the signaling mechanism for LGR7. Molecular Endocrinology 200014 1257-1271.

27 Aittomäki K, Lucena JLD, Pakarinen P, Sistonen P, Tapanainen J, Gromoll J, Kaskikari R, Sankila EM, Lehväslaiho H, Engel AR, Nieschlag E, Huhtaniemi I \& de la Chapelle A. Missense mutation 
in the ligand-binding domain of the FSH receptor gene causes hereditary hypergonadotropic ovarian failure. Cell $1995 \mathbf{8 2}$ 959-968.

28 Tena-Sempere M, Manna PR \& Huhtaniemi I. Molecular cloning of the mouse follicle-stimulating hormone receptor complementary deoxyribonucleic acid: functional expression of alternatively spliced variants and receptor inactivation by a C566T transition in exon 7 of the coding sequence. Biology of Reproduction 1999 $601515-1527$.

29 Themmen APN \& Huhtaniemi IT. Mutations of gonadotropins and gonadotropin receptors: elucidating the physiology of pitutitary-gonadal function. Endocrine Reviews 200021 551-583.

30 Ranniko A, Pakarinen P, Manna PR, Beau I, Misrahi M, Aittomäki K \& Huhtaniemi I. Functional characterization of the human FSH receptor with an inactivating Ala189Val mutation. Molecular Human Reproduction 20024 311-317.
31 Davis D, Liu X \& Segaloff DL. Identification of the sites of N-linked glycosylation on the follicle-stimulating hormone (FSH) receptor and assessment of their role in FSH receptor function. Molecular Endocrinology 19959 159-170.

32 Davis D, Rozelle TG, Liu X \& Segaloff DL. The six N-linked carbohydrates of the lutropin/choriogonadotropin receptor are not absolutely required for correct folding, cell surface expression, hormone binding, or signal transduction. Molecular Endocrinology $199711550-562$.

33 Toledo SFA \& Marino F. Inactivating mutations in the LH receptor. Fertility and Sterility 200073 655-663.

Received 11 April 2002

Accepted 5 July 2002 